\title{
Study of soil-water retention curves on a hillside from the Serra do Mar susceptible to landslides.
}

\author{
Lidiane C. Nogueira*, Carolina V. Perdomo, Miriam G. Miguel
}

\begin{abstract}
Gravitational mass movements are processes of solid matter transport and exogenous modelling of the relief. In Brazil, the landslides are the most common type, for its climatic and geological dynamics, triggered mainly by rainfall. Particularly, Serra do Mar has become a scene of great incidence these events, due to its climatic, geological and geomorphological characteristics. This research has the objective to develop the modelling of soil-water retention curves of the soil samples collected from B e and C-horizons of four open trenches in a hillside from the Serra do Mar. The soil-water retention curves were studied with drying and wetting pathways. It is aimed to understand of the water flow and possible destabilization processes in the hillside.
\end{abstract}

\section{Key words:}

Soil-water retention, landslides, Serra do Mar.

\section{Introduction}

Gravitational mass movements are a process of solid matter transport, differentiated by material type, velocity, movement mechanisms, deformation mode, mass geometry and moisture content. The rain is the main triggering these movements in Brazil, especially the landslides (the most common type) by their ability to infiltrate and raise the level of water in the soil, which may increase percolation forces by temporarily filling cracks, creating "saturation fronts" by increasing hydrostatic pressures. Therefore, this research proposes an analysis of the flow of water in the soil, from the soil-water retention curves (SWRC) in drying and wetting pathways. The horizons $B$ and $C$ (about recurrence of the events of landslides in the deepest horizons) of four trenches (1, 3, 7 and 9) opened on the hillside on the Serra do Mar were studied, in order to understand the processes conditioning to landslides.

\section{Results and Discussion}

Soil-water retention curves obtained for the drying and wetting pathways can be seen in Figure 1, for example, representing the relationship between the amount of water and the matric suction of the soil. Both curves were modelled using the Equation (1) proposed by Van Genuchten (1980).

$$
w=\frac{w_{\text {res }}-w_{\text {sat }}}{\left[1+(\alpha \Psi)^{\mathrm{n}}\right]^{\mathrm{n}}}+w_{\text {res }}
$$

Where:

$\mathrm{W}_{\text {res }}=$ residual gravimetric moisture content (\%)

$\mathrm{w}_{\text {sat }}=$ saturated gravimetric moisture content $(\%)$

$\Psi=$ matrix suction in module $(\mathrm{kPa})$

$\alpha\left(\mathrm{KPa}^{-1}\right)$ and $" \mathrm{~m}$ " and " $\mathrm{n}$ " independent parameters that must be estimated and adjusted by trial and error.

The parameters " $\alpha$ ", " $n$ "' and " $m$ " are related to the shape of the SWRC. The greater the value of " $a$ " the higher the input (drying pathway) or output (wetting pathway) air value in the soil. Value of parameter " $n$ " causes the retention curve to rotate around the inflection point. The increase in the value of " $m$ " causes that, for high suction values, the retention curve approaches the axis of the abscissa.

Soils with predominance of macroporosity present SWRC of the unimodal type. While soils presenting macro and microporosity, these curves are of the bimodal type (Figure 1). All the soil samples from C-horizon presented SWRC of the bimodal type. Soils samples from B-horizon of the TR01 and TR07 presented SWRC of the unimodal type and those of TR03 and TR09 bimodal type.

Figure 1. Soil-water retention curves in drying and wetting pathways (TR3 - B).

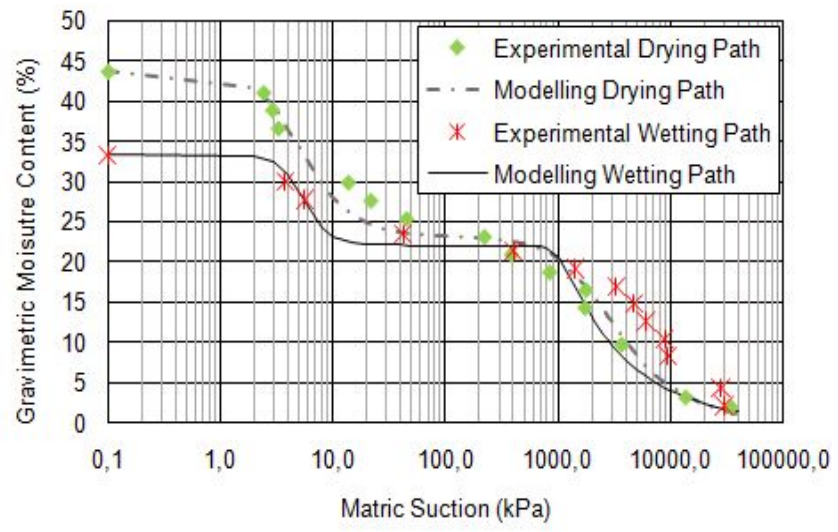

In addition, all soil samples presented the hysteresis phenomenon, which is expressed by the non-coincidence of the SWRC obtained in the drying and wetting pathways (Figure 1 for example). In general, SWRC presented low values of " $\alpha$ ", representing relatively large pores that allow the onset of air input or output in low suction values. This fact is characteristic of granular soils like the sands and corroborates with the textural classification of soil samples as silty sands.

\section{Conclusions}

Soil-water retention curves were influenced by the macro and/or microporosity and by texture of the soil samples collected in horizons $\mathrm{B}$ and $\mathrm{C}$. The macroporosity and the granular texture were predominant in the soil samples, facts that allow a greater ease of percolation of the water to deeper horizons, guaranteeing good drainage and good aeration, but with less water retention. Therefore, more studies should be developed in the hillside collaborating for a better understanding of these conditionings to landslides.

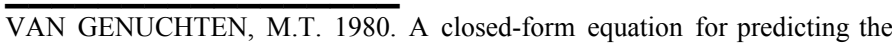
hydraulic conductivity of unsaturated soils. Soil Sci. Soc. Am. J., 44:892-898. 